\title{
Neutrophil Gelatinase-Associated Lipocalin: Ready for Routine Clinical Use? An International Perspective
}

\author{
Claudio Ronco ${ }^{a}$ Matthieu Legrand ${ }^{d}$ Stuart L. Goldstein ${ }^{e}$ Mina Hur ${ }^{\text {h }}$ Nam Tran $^{f}$ \\ Eric C. Howell ${ }^{f}$ Vincenzo Cantaluppi ${ }^{b}$ Dinna N. Cruz ${ }^{g}$ Kevin Damman $^{i}$ \\ Sean M. Bagshaw ${ }^{j}$ Salvatore Di Sommac Andrew Lewington ${ }^{k}$ \\ ${ }^{a}$ Department of Nephrology, Dialysis and Transplantation, International Renal Research Institute, San Bortolo Hospital, \\ Vicenza, ${ }^{b}$ Nephrology, Dialysis and Antonio Vercellone Kidney Transplantation Unit, University of Torino, Torino, and

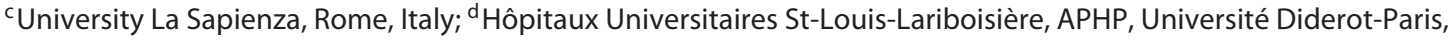 \\ Paris, France; ' University of Cincinnati College of Medicine and Center for Acute Care Nephrology, Cincinnati Children's \\ Hospital Medical Center, Cincinnati, Ohio, ${ }^{\mathrm{f} U n i v e r s i t y ~ o f ~ C a l i f o r n i a ~ D a v i s ~ S c h o o l ~ o f ~ M e d i c i n e, ~ S a c r a m e n t o, ~ C a l i f ., ~ a n d ~}$ \\ gDivision of Nephrology-Hypertension, University of California, San Diego, Calif., USA; \\ ${ }^{h}$ Konkuk University School of Medicine, Seoul, Korea; 'University Medical Center Groningen, Groningen, \\ The Netherlands; ${ }^{j}$ Division of Critical Care Medicine, University of Alberta, Edmonton, Alta., Canada; \\ ${ }^{k}$ Department of Renal Medicine, St James's University Hospital, Leeds, UK
}

\section{Key Words}

Neutrophil gelatinase-associated lipocalin - Acute kidney injury · Chronic kidney disease

\footnotetext{
Abstract

Acute kidney injury (AKI) remains a challenge in terms of diagnosis and classification, its morbidity and mortality remaining high in the face of improving clinical protocols. Current clinical criteria use serum creatinine $(\mathrm{s} C r)$ and urine output to classify patients. Ongoing research has identified novel biomarkers that may improve the speed and accuracy of patient evaluation and prognostication, yet the route from basic science to clinical practice remains poorly paved. International evidence supporting the use of plasma neutrophil gelatinase-associated lipocalin (NGAL) as a valuable biomarker of AKI and chronic kidney disease (CKD) for a number of clinical scenarios was presented at the 31st International Vicenza Course on Critical Care Nephrology, and these data are detailed in this review. NGAL was shown to be highly
}

useful alongside $\mathrm{s} C \mathrm{r}$, urinary output, and other biomarkers in assessing kidney injury; in patient stratification and continuous renal replacement therapy (CRRT) selection in paediatric AKl; in assessing kidney injury in conjunction with $\mathrm{sCr}$ in sepsis; in guiding resuscitation protocols in conjunction with brain natriuretic peptide in burn patients; as an early biomarker of delayed graft function and calcineurin inhibitor nephrotoxicity in kidney transplantation from extended criteria donors; as a biomarker of cardiovascular disease and heart failure, and in guiding CRRT selection in the intensive care unit and emergency department. While some applications require further clarification by way of larger randomised controlled trials, NGAL nevertheless demonstrates promise as an independent biological marker with the potential to improve earlier diagnosis and better assessment of risk groups in AKI and CKD. This is a critical element in formulating quick and accurate decisions for individual patients, both in acute scenarios and in long-term care, in order to improve patient prognostics and outcomes.

(c) 2014 S. Karger AG, Basel

\section{KARGER}

E-Mail karger@karger.com

www.karger.com/bpu
(C) 2014 S. Karger AG Basel

0253-5068/14/0374-0271\$39.50/0
Dr. Claudio Ronco

Department of Nephrology, San Bortolo Hospital

Viale Rodolfi 37

IT-36100 Vicenza (Italy)

E-Mail cronco@goldnet.it 


\section{Biomarker of Injury, Not Function [1]}

Biomarkers such as plasma neutrophil gelatinase-associated lipocalin (NGAL) can serve not only in the diagnostic and prognostic realm, but in reaching a deeper understanding of the pathophysiological factors that guide the progression of the disease in question. A significant reservation regarding the clinical use of NGAL arises from reported discrepancies in receiver-operating characteristic (ROC) analyses [2], but this unreliability may be explained by a number of factors, which can only be understood by scrutiny of the methodologies and hypotheses of clinical trials [3]. Hence, we may gain an understanding of why some studies fail and, importantly, identify more clearly which endpoints can answer specific clinical questions.

One of the factors introducing variability to area under curve (AUC) values in ROC analysis is in the choice of commercial assay, a challenge relating to biomarkers in general (fig. 1). These differences can be minimised by consistent use of a single assay.

Paragas et al. [5] demonstrated the viability of NGAL as a marker specifically of injury by showing its expression by injured cells, and the corresponding increase in urinary NGAL, in a NGAL reporter mouse model. NGAL expression was increased following ischaemia-reperfusion (I/R) injury in an NGAL reporter mouse model. By then, inducing renal volume depletion [which can be a confusing factor in acute kidney injury (AKI) diagnosis], serum creatinine ( $\mathrm{sCr}$ ) levels increased and creatinine (Cr) clearance decreased, indicating reduced renal function, while NGAL levels were unchanged.

Paragas et al. [5] then examined endotoxaemia in the mouse model, in which the kidney was targeted but every organ was in sepsis, and NGAL expression increased accordingly in the lung, liver, spleen, trachea, and kidney. In this systemic inflammatory state, such elevation of plasma NGAL suggests that it may not always be effective in AKI prediction in cases of suspected sepsis.

The various aetiologies of kidney insult make for difficult diagnosis and risk assessment. $\mathrm{Cr}$, a functional biomarker, is complemented by NGAL, allowing for the distinction of kidney injury in individuals with otherwise optimal kidney function, as well as in chronic kidney disease (CKD) patients where the same injury would give rise to a significant decrease in $\mathrm{Cr}$ clearance and renal function.

Biomarkers of injury and of function can be applied as two different exploratory tools in the clinical setting: (i) to understand the processes affecting renal function from

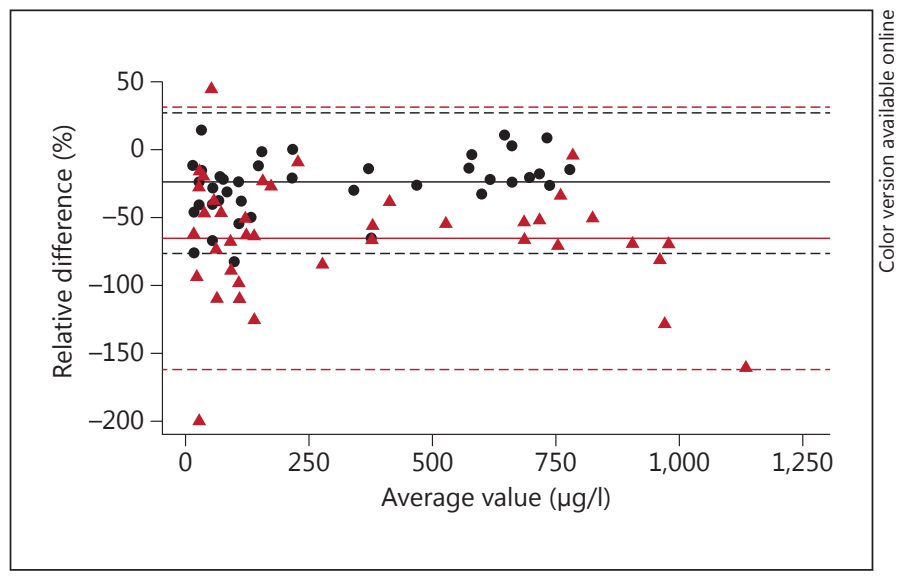

Fig. 1. Relative differences between urinary NGAL commercial assays [4]. Each symbol represents a different commercial NGAL assay.

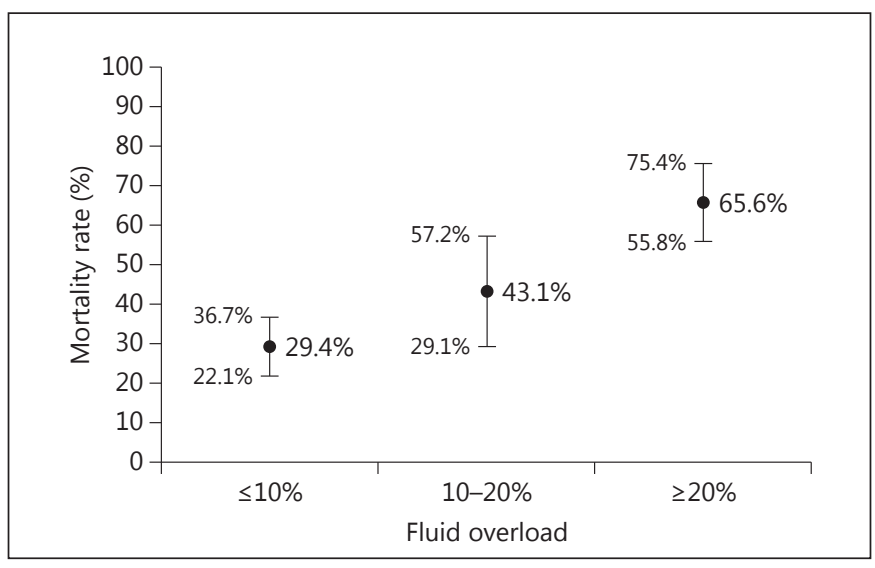

Fig. 2. Fluid overload and mortality in children receiving CRRT: The Prospective Paediatric Continuous Renal Replacement Therapy Registry [8].

hypoperfusion, hypertension and drug dosing, and how these affect prognoses, and (ii) to understand the processes affecting renal injury and the ways in which patients with injury but normal function compare to patients with little or minor injury and decreased renal function.

Outstanding clinical questions in AKI stem from its still poorly understood pathophysiology. Novel biomarkers such as NGAL could provide more information with which to make more accurate prognoses. With prognostic balance being achieved by considering independent biomarkers of injury and function, NGAL offers tremendous potential as one valuable biomarker to improve this decision-making processes. 
Fig. 3. Outline of Taking Focus study protocol [7].

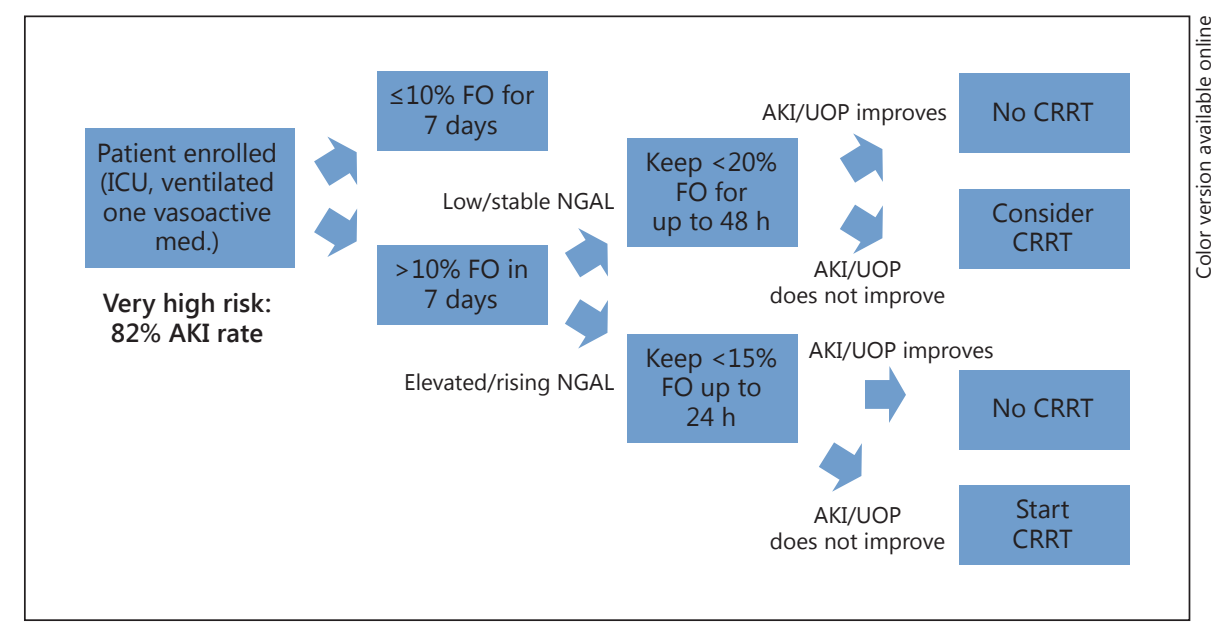

\section{Paediatric Acute Kidney Injury [6]}

The use of NGAL to refine knowledge of at-risk populations could help to predict paediatric AKI development and severity for its better management and prevention, and could ultimately reduce the overall disease burden. Two trials recently initiated by Stuart L. Goldstein at the Children's Hospital Medical Center, Cincinnati, are capitalising on previous NGAL work by investigating it as a biomarker in paediatric AKI.

\section{Trial in AKI Using NGAL and Fluid Overload to Optimize CRRT Use (Taking Focus)}

Taking Focus [7] investigates the use of NGAL in early detection of AKI in paediatric cases in order to predict its severity, which would serve to optimise the initiation of fluid administration and dialysis. Paediatric studies have demonstrated an independent association between fluid overload at CRRT initiation and poor outcome, suggesting that earlier dialysis may improve survival.

Previous work by Sutherland et al. [8] suggests that the rate of mortality increases when patients reach $>10 \%$ fluid overload at intensive care unit (ICU) initiation (fig. 2). Patient mortality rates increased from $30 \%$ at $<10 \%$ fluid overload, to $43 \%$ at $10-20 \%$ fluid overload, and $66 \%$ at $>20 \%$ overload. Importantly, patients in the $10-20 \%$ fluid overload group were found to be in significantly worse health than patients in the $<10 \%$ fluid overload group by every available metric. At $>20 \%$ fluid overload, patients were sicker by every metric than those with $10-20 \%$ fluid overload.

An association between percentage fluid overload (fluid in vs. fluid out as a proportion of body weight in pa- tients entering the ICU) and point-of-care (POC) plasma and confirmatory urinary NGAL concentrations would suggest a applicable predictive mechanism. Taking Focus will then determine if NGAL can predict which critically ill patients that developed significant fluid overload will recover urine output and kidney function rapidly. In addition, it will determine if NGAL concentrations could predict kidney function in critically ill children who develop $>10-20 \%$ ICU fluid overload who then go on to CRRT.

The Taking Focus protocols depend on the state of the patient defined by metrics such as percentage fluid overload and rate of change of NGAL levels (fig. 3). As such, it is preliminary to the development of a randomised trial of early CRRT versus standard care.

\section{NGAL Directed Randomisation of Fenoldopam after Cardiopulmonary Bypass}

The second prospective trial focuses on NGAL as a tool to select subjects in studies of paediatric cardiac bypass. Previous work by Ricci et al. [9] demonstrated the use of NGAL and cystatin C as markers of AKI amelioration by fenoldopam administration in paediatric patients undergoing cardiac surgery. In this study, fenoldopam significantly decreased urinary cystatin C levels at ICU arrival (following surgery) when compared with placebo, as well as significantly decreasing NGAL levels when compared to controls both at ICU arrival and at $12 \mathrm{~h}$ post-ICU arrival. However, while these were seminal findings, to their detriment they did not incorporate risk stratification; hence, it is possible that $60 \%$ of the children who received fenoldopam would not have developed AKI at all. 
Emerging from these observations, the proposed pilot trial incorporates POC NGAL measures $2 \mathrm{~h}$ after cardiopulmonary bypass in order to enrich the population to be randomised. Patients with high NGAL are randomised to fenoldopam or placebo, while patients with normal NGAL are not treated or randomised with the assumption that they do not have AKI, although they will be observed.

NGAL will be used in this inventive manner as a tool to aid subject selection, whereas Taking Focus examines the value of NGAL in a more direct sense - in predicting the course of fluid accumulation and kidney injury. Clearly, positive results will forecast NGAL as a biomarker in subject selection and as a tool to guide CRRT initiation.

\section{Plasma NGAL as a Biomarker for AKI in Critically III Patients with Suspected Sepsis [10]}

Sepsis, a systemic inflammatory response syndrome combined with a known or suspected infection, is a major contributing factor to AKI in critically ill patients, with a distinct pathophysiological profile. Current approaches in the management of renal dysfunction in sepsis could be improved by the additional use of NGAL, which is not currently used in clinical practice, based on evidence demonstrating it to be a highly sensitive and objective predictive marker of kidney injury in suspected cases of sepsis [11].

Sepsis is associated with haemodynamic organ dysfunction, tissue perfusion abnormalities, and increased C-reactive protein (CRP) and procalcitonin (PCT) levels $[12,13]$. The use of PCT and CRP have improved the diagnosis and staging of sepsis. PCT is a relatively new biomarker of systemic inflammation, infection and sepsis [14]. Relative to CRP, PCT shows better specificity, time advantage, and a close relationship with the development of sepsis and with clinical outcome $[15,16]$.

The sepsis-related organ failure assessment (SOFA) score has been used to describe multiple organ failure in sepsis, comprising six different subscores pertaining to the function of each organ. In current clinical settings, the diagnosis of AKI is based on Acute Kidney Injury Network (AKIN) criteria. AKIN criteria use sCr concentration and urine output for AKI diagnosis. However, the AKIN criteria states that $\mathrm{sCr}$ and urine output are used because sensitive markers of kidney injuries are not currently in practice.

Kim et al. [11] investigated the value of NGAL as a diagnostic and staging tool in AKI in critically ill patients with suspected sepsis by way of a single-centre study, questioning whether or not plasma NGAL is associated with PCT, and whether plasma NGAL concentrations differ according to the grade of sepsis. Diagnosing AKI based on the AKIN criteria, patients were divided into five groups based on their renal subscore of SOFA score as dictated by $\mathrm{sCr}$ and urine output. Patients were also divided according to stage of sepsis, as dictated by PCT concentrations, into five groups ranging from healthy (group I) through to systemic infection or sepsis (group III) and septic shock (group V).

Kim et al. demonstrated increasing renal subscore of SOFA score according to sepsis severity. When compared to PCT concentrations, the median value of plasma NGAL was above the medical decision point of $150 \mathrm{ng} / \mathrm{ml}$ in septic patients (groups III-V) (fig. 4). In a comparison of NGAL concentrations below and above this medical decision point, plasma NGAL was found to be significantly higher in septic patients than in non-septic patients (fig. 5).

Plasma NGAL was significantly associated with the renal subscore of SOFA score, whereas sCr concentrations were found to be above the medical decision point only in patients with septic shock. Plasma NGAL was also significantly higher in AKI patients than in non-AKI patients. However, there was no significant difference in plasma NGAL between septic patients with AKI and those without AKI.

The work of Kim et al. [11] provides the first evidence for the use of NGAL, in conjunction with $\mathrm{Cr}$, in determining kidney function and injury for the improved assessment of kidney injury in the diagnosis of sepsis. NGAL correlated well with PCT in sepsis diagnosis and staging. These findings suggest the great value of NGAL in sepsis, although a prospective randomised trial would provide further validation.

\section{Point-of-Care BNP and NGAL for Acute Resuscitation in Severely Burned Patients [17]}

Burn patients are at high risk for infection and organ failure. Early AKI during burn shock is associated with early multiple organ dysfunction and higher mortality risk [18]. Elaborate water loss and inflammatory responses may result in hypovolaemia and shock, the burn shock period', requiring significant fluid resuscitation to offset organ perfusion issues as well as iatrogenic pathologic sequelae due to intervention. The reliable and quick recognition of under- or over-resuscitation in at-risk patients 


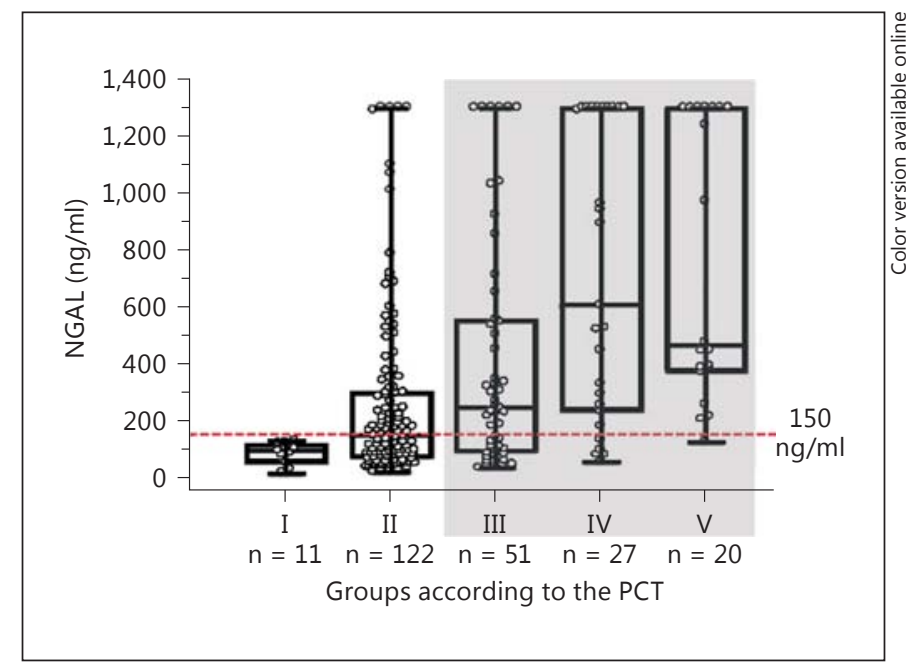

Fig. 4. Plasma NGAL concentrations according to the PCT groups were $95(16-129) \mathrm{ng} / \mathrm{ml}, 149(19-1,300) \mathrm{ng} / \mathrm{ml}, 245(33-1,300) \mathrm{ng} /$ $\mathrm{ml}, 605(55-1,300) \mathrm{ng} / \mathrm{ml}$, and $462(127-1,300) \mathrm{ng} / \mathrm{ml}$, respectively. Septic patient groups (groups III-V, as dictated by PCT concentrations) displayed median plasma NGAL concentrations above the medical decision point of $150 \mathrm{ng} / \mathrm{ml}$ [11].

is a clear unmet clinical need. The characterisation of POC serum B-type natriuretic peptide (BNP) and NGAL levels during fluid resuscitation for severe burn injury is being investigated as part of an ongoing study at UC Davis School of Medicine.

Current resuscitation strategies involve the calculation of rehydration fluid volumes according to the Parkland formula [ $4 \mathrm{ml} / \mathrm{kg}$ body $/ \%$ total body surface area (TBSA)] for the first $24 \mathrm{~h}$. This is titrated based on urine output, based on a maintenance rate [19]. Yet TBSA can be inaccurate, not least because of the increasing prevalence of obesity. Furthermore, urine output may adequately monitor clinical progress. High urine output may not be representative of renal status, as glomerular filtration rate (GFR) can alter while urine output remains the same in a critical illness. $\mathrm{sCr}$ concentration is affected by age, gender, muscle mass and nutritional status. A significant rise in $\mathrm{sCr}$ can only occur after a large amount of nephronal damage has occurred, and sCr has a half-life of approximately $4 \mathrm{~h}$.

POC testing may provide a solution for rapid biomarker characterisation in burn patients. BNP has been shown to be predictive of over-resuscitation [20], as NGAL has of AKI [21]. These two biomarkers combined improves the sensitivity and specificity of detecting AKI, and this is possibly attributed to cardiorenal syndrome, the linkage between these two organs where one becoming dysfunctional can affect the other [22].

NGAL: Ready for Routine Clinical Use?

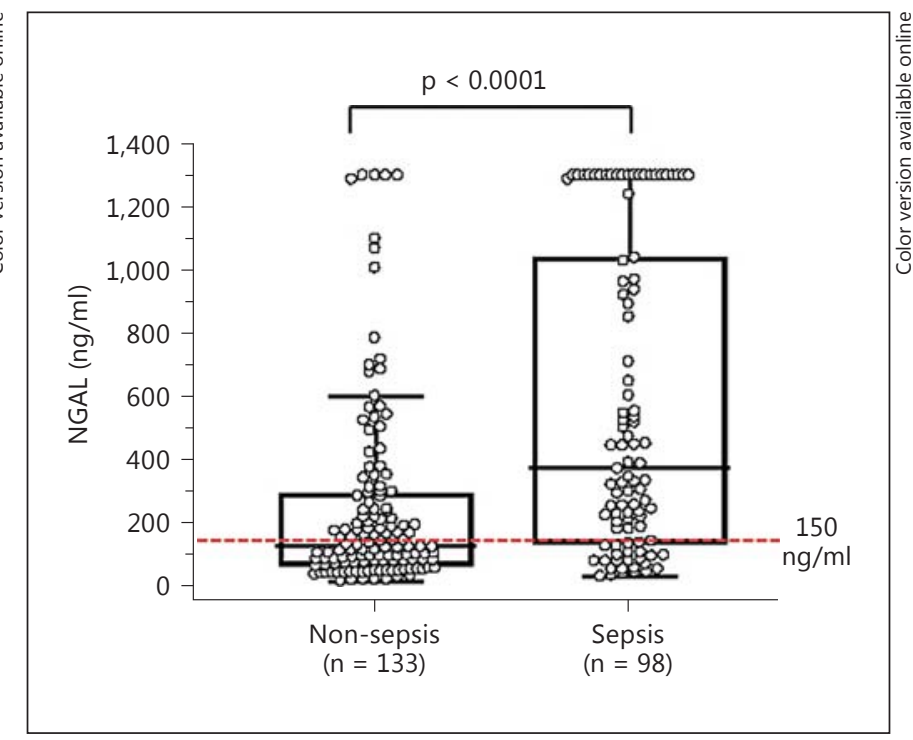

Fig. 5. Plasma NGAL was significantly higher in septic patients (groups III-V) than in non-septic patients (groups I and II) (337.5 vs. $129.0 \mathrm{mg} / \mathrm{ml}, \mathrm{p}<0.0001)$ [11].

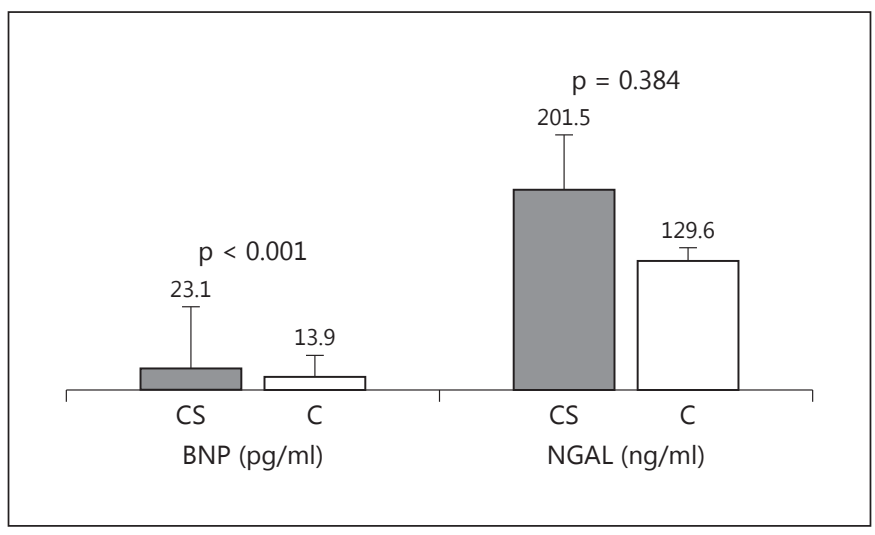

Fig. 6. Comparison of BNP and NGAL concentrations between the compartment syndrome cohort $(C S, n=5)$ and controls $(C, n=10)$.

The ongoing prospective study at UC Davis School of Medicine hypothesises the predictive value of BNP and NGAL of inadequate resuscitation in severely burned patients, with severe burns being $\geq 20 \%$ TBSA. POC testing for sCr, BNP and NGAL was carried out every $2 \mathrm{~h}$ during the first $48 \mathrm{~h}$ of admission during fluid resuscitation, and these were correlated with traditional indicators of fluid resuscitation. Whole blood samples were taken every $2 \mathrm{~h}$ during the first $48 \mathrm{~h}$ of admission. Primary endpoints were defined as AKI using RIFLE (risk, injury, failure, loss 
Fig. 7. Incidence of DGF in kidney transplantation over the last years (data from the 'A. Vercellone' Kidney Transplantation Center, University of Torino).

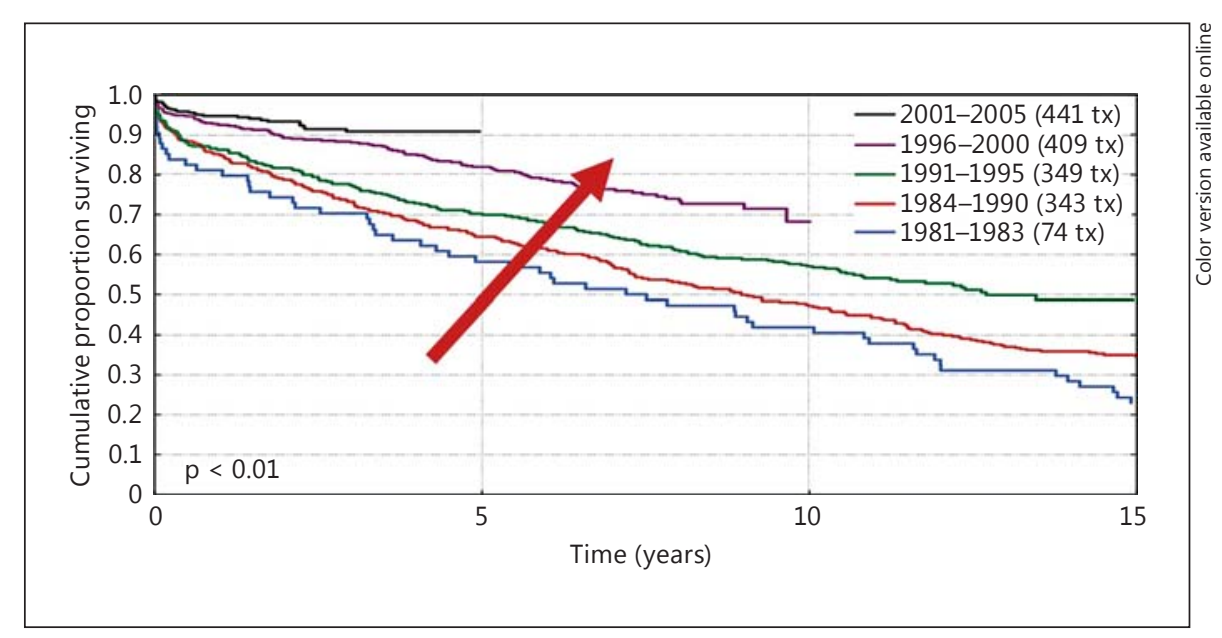

and end-stage renal disease) criteria, within the first $48 \mathrm{~h}$ of admission, and abdominal or limb compartment syndrome. Secondary endpoints included BNP, NGAL and Cr levels. Preliminary results suggest that BNP and NGAL concentrations are significantly higher in AKI patients than in the non-AKI patients. Time-course data relating to NGAL and $\mathrm{Cr}$ indicate that NGAL concentrations rise 4-8 h earlier than those of $\mathrm{Cr}$ in the AKI group with respect to the non-AKI group. In a comparison of compartment syndrome $(n=5)$ with controls $(n=10)$, BNP differed significantly (fig. 6), while differences in NGAL and Cr were not significant.

There is evidence to suggest that the significant risks associated with fluid over- or under-resuscitation could be ameliorated via a combination of predictive biomarkers that can be employed quickly and reliably. While only BNP significantly discriminated compartment syndrome patients from controls, this ongoing investigation forms the basis of further interventional studies into the use of POC testing of NGAL and BNP to guide resuscitation protocols in burn patients.

\section{Plasma NGAL as an Early Biomarker of Delayed Graft Function in Kidney Transplantation from Extended Criteria Donors [23]}

Although kidney graft survival has increased substantially over the past years due to improvements in immunosuppressive techniques, the use of biomarkers such as NGAL in assessing the risk of delayed graft function (DGF) could further benefit survival rates, especially in the higher-risk extended criteria cohort. Ongoing work at the University of Torino, Italy, finds evidence supporting the use of plasma NGAL in DGF and calcineurin inhibitor (CNI) nephrotoxicity.

Kidney transplantation represents the best therapeutic option for patients with CKD; mortality after transplantation is significantly lower than that observed in patients on dialysis who remain on the waiting list [24]. DGF is a form of AKI occurring early after transplantation and is usually defined as the need for dialysis in the first week following transplantation. Although kidney survival rates have improved over recent decades, loss of kidney graft function occurs due to either immunological or non-immunological factors; the latter includes classical AKI, as well as transplantation-related causes such as I/R injury and CNI nephrotoxicity.

Given the association of shorter pre-transplantation dialysis duration with both transplantation and patient survival, the use of extended criteria donors (ECDs), as well as donor matching (the so-called 'old-for-old' strategy) has expanded the donor pool effectively [25]. ECDs are characterised as those over the age of 60 , or over 50 years with two additional risk factors out of diabetes, hypertension and $\mathrm{sCr}>1.5 \mathrm{mg} / \mathrm{dl}$. Data from the University of Torino (fig. 7) showed that the incidence of DGF has remained high in the last years (persistently more than $25 \%$ in the period 2008 $2012 ; 27.39 \%$ only in 2012). Furthermore, DGF is more frequent in kidney transplantation from ECDs.

DGF is a major predictor of renal allograft failure [26]. Indeed, graft damage following I/R injury may lead to exposure of hidden antigens with the consequent triggering of both cell-mediated and humoral immune system activation. Early biomarkers such as NGAL could therefore provide a means of anticipating DGF in order to subdue the 


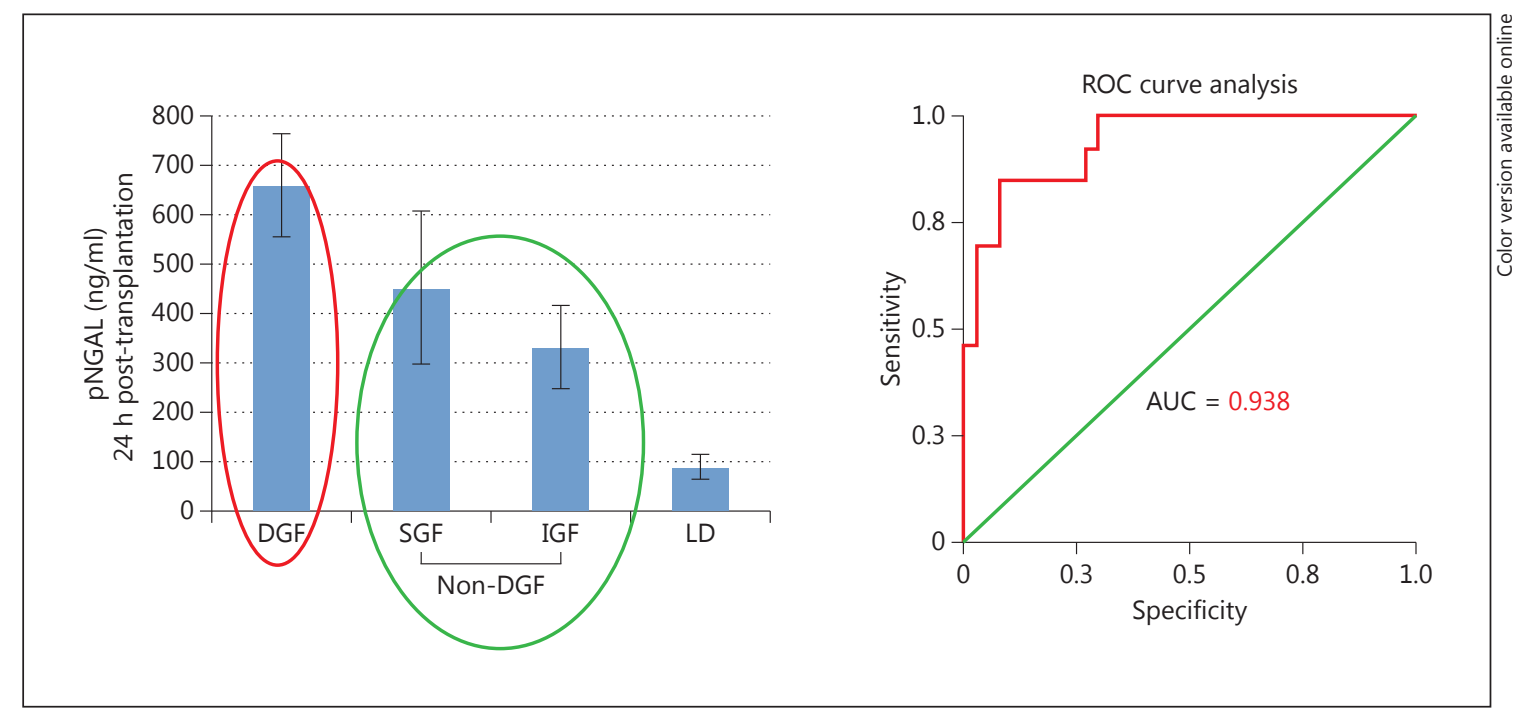

Fig. 8. Plasma NGAL levels $24 \mathrm{~h}$ following kidney transplantation from ECDs. DGF was associated with significantly higher levels of NGAL compared with non-DGF group $(\mathrm{n}=25)$. Plasma NGAL levels $>400 \mathrm{ng} / \mathrm{ml}$ seem to be predictive of DGF (data from the 'A. Vercellone' Kidney Transplantation Center, University of Torino).

inflammatory mechanisms that propagate its development $[27,28]$. Urinary NGAL and IL-18 have been shown to predict dialysis and DGF in donors matching conventional criteria [29]. In a preliminary study, Cantaluppi et al. at the 'A.Vercellone' Kidney Transplantation Unit correlated plasma NGAL level to DGF incidence in a study of 25 consecutive kidney transplantations from ECDs. Cantaluppi [23] showed that, in the first $24 \mathrm{~h}$ following transplantation, patients with DGF demonstrated higher concentrations of plasma NGAL compared to non-DGF patients (fig. 8). Moreover, in a small cohort of patients followed 1 year after transplantation, patients with DGF showed a worse renal function than non DGF patients [sCr $1.82 \pm$ $0.61 \mathrm{mg} / \mathrm{dl}$ DGF group vs. $1.4 \pm 0.54 \mathrm{mg} / \mathrm{dl}$ non-DGF group; estimated GFR (eGFR) $54 \pm 9 \mathrm{ml} / \mathrm{min}$ DGF group vs. $65 \pm 11 \mathrm{ml} / \mathrm{min}$ non-DGF group]. These results support the hypothesis that NGAL may be marker of dedifferentiation and a crucial factor for the development of tubulointerstitial fibrosis and CKD progression [30]. However, recent experimental studies showed that NGAL may also act as a growth factor, promoting tubular epithelial cell survival through the inhibition of apoptosis after I/R injury.

In the setting of kidney transplantation from ECDs, there is evidence to support the use of plasma NGAL as an early indicator of graft function that may discriminate between DGF and non-DGF patients. Moreover, NGAL correlates better with DGF than existing risk prediction models.

NGAL: Ready for Routine Clinical Use?

\section{NGAL as a Biomarker of Cardiovascular Disease [31]}

The involvement of NGAL in the pathophysiology of CVD is well documented, with elevated NGAL levels being reported in heart failure, coronary heart disease, and stroke. However, the predictive value of NGAL, and its role in the clinic, requires further investigation.

The co-localisation of matrix metalloproteinases (MMPs), which play a very important role in vascular remodelling and plaque stability in atherosclerotic disease, and NGAL has been shown both in murine models of atherosclerosis [32], as well as in human abdominal aortic aneurysm [33].

MMPs are released when a plaque becomes inflamed, with accumulation of macrophages and $\mathrm{T}$ lymphocytes. MMPs digest collagen within the plaque, leading to instability of the fibres of the plaque, such that it is more susceptible to rupture. Under normal conditions, the degradative effect of MMPs is highly regulated by the presence of endogenous inhibitors such as tissue inhibitor of metalloproteinases-2 (TIMP-2). NGAL, by forming a stable dimer with MMPs, protects MMPs from TIMP-2, thereby enhancing the proteolytic digestion of collagen, leaving plaques more susceptible to erosion and rupture.

In a systematic review of studies of cardiovascular disease (excluding AKI and renal endpoints), Cruz et al. [34] demonstrated that systematic NGAL levels were higher in CVD patients than in non-CVD patients. In the same re- 


\begin{tabular}{|c|c|c|c|c|c|c|}
\hline & \multicolumn{2}{|c|}{ Cardiovascular mortality } & \multicolumn{2}{|l|}{ All-cause mortality } & \multicolumn{2}{|c|}{ Combined cardiovascular endpoint } \\
\hline & $\mathrm{HR}(95 \% \mathrm{CI})$ & $p$ value & $\mathrm{HR}(95 \% \mathrm{CI})$ & $p$ value & $\mathrm{HR}(95 \% \mathrm{CI})$ & $p$ value \\
\hline Number of deaths/events & 169 & & 436 & & 254 & \\
\hline Unadjusted & $1.72(1.47-2.01)^{\mathrm{b}}$ & $<0.001$ & $1.48(1.34-1.64)^{\mathrm{b}}$ & $<0.001$ & $1.48(1.30-1.69)^{\mathrm{b}}$ & $<0.001$ \\
\hline Model 1 & $1.34(1.15-1.58)^{b}$ & $<0.001$ & $1.22(1.10-1.35)^{\mathrm{b}}$ & $<0.001$ & $1.29(1.13-1.47)^{b}$ & $<0.001$ \\
\hline Model 2 & $1.33(1.12-1.57)^{\mathrm{c}}$ & 0.001 & $1.19(1.07-1.32)^{\mathrm{c}}$ & 0.001 & $1.26(1.10-1.45)^{c}$ & 0.001 \\
\hline \multicolumn{7}{|l|}{ Model 3} \\
\hline NGAL & $1.25(1.05-1.48)$ & 0.01 & $1.14(1.03-1.28)$ & 0.02 & $1.21(1.05-1.39)$ & 0.01 \\
\hline NT-proBNP & $1.80(1.48-2.18)^{\mathrm{b}}$ & $<0.001$ & $1.42(1.26-1.61)^{b}$ & $<0.001$ & $1.52(1.29-1.79)^{\mathrm{b}}$ & $<0.001$ \\
\hline CRP & $1.09(0.90-1.31)$ & 0.38 & $1.06(0.95-1.19)$ & 0.29 & $1.08(0.93-1.26)$ & 0.31 \\
\hline
\end{tabular}

Fig. 9. Multivariate Cox proportional hazards model for risk of death or CVD per 1 SD increase in $\log _{10}$ NGAL and other biomarkers, indicating that NGAL is an independent predictor of outcome. Steps: (1) age, sex; (2) previous step + DM, HTN, smoking, SBP, chol, HDL, CrCl, BMI; (3) previous steps + NT-proBNP, CRP [37]. ${ }^{\mathrm{a} C o m b i n e d ~ c a r d i o v a s c u l a r ~ e n d p o i n t ~ i s ~ c o r o n a r y ~ r e v a s c u l a r i z a t i o n, ~}$ myocardial infarction, or CVD death; ${ }^{b}$ values are significant at $\mathrm{p}<$ 0.001 ; $^{\mathrm{c}}$ values are significant at $\mathrm{p}=0.001$. view, is was shown that, in heart failure patients, NGAL correlated with other biomarkers of renal function and with CVD clinical severity, although reporter bias may have prevented non-correlating results from being published. In the same review, the relationship of plasma NGAL with mortality and major adverse cardiac events was investigated using data from six studies of biomarkers in chronic and acute heart failure or stroke. Combined high NGAL and high BNP concentration was associated with a 30 -fold increase in risk of rehospitalisation or death, compared with those with low NGAL and BNP at discharge. While these data appear strong, generally small sample sizes and minimal control of confounding factors leave the data somewhat unreliable [35].

While the correlation between NGAL and markers of CVD has subsequently been reported in larger studies, Nymo et al. [36] suggested NGAL to be a surrogate marker of severity of heart failure and inflammation. NGAL was not found to independently predict mortality, cardiovascular disease or hospitalisation when data were adjusted for confounding factors (such as cardiovascular risk, function, and high-sensitivity CRP (hsCRP) and N-terminal pro-BNP (NT-proBNP)).

More recently, Daniels et al. [37] provided further elucidation as to the viability of NGAL as an independent marker. By excluding NGAL from their fully-adjusted analysis, both $\mathrm{Cr}$ clearance and CRP no longer reached statistical significance, indicating that NGAL is indeed an independent marker of CVD (fig. 9).

Highly expressed in the heart and atherosclerotic plaques, NGAL correlates with CVD severity and may be an independent predictor of major adverse cardiac events and mortality as evidenced in some, but not all, studies. While further work is required to determine the place of NGAL in clinical management, it has the potential to provide unique clinical information alongside other biomarkers for the management of cardiorenal and cardiovascular disease.

\section{Heart Failure [38]}

Heart failure outcome is predicted by renal impairment more than it is by cardiac functional impairment [39], and decreased renal function in heart failure could stem from impaired venous function that leads to structural renal damage. Evidence suggests that NGAL reflects disease severity in heart failure and acts as a sensitive predictive marker in both acute and chronic cases.

Decrease in renal function is a potent predictor of mortality. Increased venous and renal congestion and renal venous pressure is a characteristic of acute heart failure, in addition to structural damage such as microalbuminuria. Few animal experimental models estimate cardiorenal damage as an approximation of functional decline in GFR. Yet a study by Entin-Meer et al. [40] in a rat model of cardiorenal syndrome demonstrated elevated urinary NGAL with subtotal nephrectomy and myocardial infarction in the presence of acute nephronal deterioration.

Prior work by Damman et al. [41] demonstrated an increase in urinary NGAL levels, in addition to a decrease in eGFR, in patients with chronic heart failure compared 


\begin{tabular}{|c|c|c|c|c|c|c|c|c|c|c|}
\hline \multirow{3}{*}{$\begin{array}{l}\text { Study or } \\
\text { subgroup }\end{array}$} & \multicolumn{2}{|l|}{ WRF } & \multicolumn{2}{|c|}{ No WRF } & \multirow[t]{2}{*}{ weight, \% } & \multirow{2}{*}{$\begin{array}{l}\text { Odds ratio } \\
\mathrm{M}-\mathrm{H} \text {, random }(95 \% \mathrm{CI})\end{array}$} & \multirow{2}{*}{ year } & \multirow{2}{*}{\multicolumn{3}{|c|}{$\begin{array}{l}\text { Odds ratio } \\
\mathrm{M}-\mathrm{H} \text {, random }(95 \% \mathrm{CI})\end{array}$}} \\
\hline & \multirow{2}{*}{$\begin{array}{c}\text { events } \\
119\end{array}$} & \multirow{2}{*}{$\begin{array}{r}\text { total } \\
469\end{array}$} & \multirow{2}{*}{$\begin{array}{r}\text { events } \\
235\end{array}$} & \multirow{2}{*}{$\begin{array}{r}\text { total } \\
1,212\end{array}$} & & & & & & \\
\hline & & & & & 7.1 & $1.41(1.10,1.82)$ & 2000 & & $\tau$ & \\
\hline Smith & 35 & 185 & 27 & 227 & 5.0 & $1.73(1.00,2.98)$ & 2003 & & C. & \\
\hline Forman & 19 & 273 & 7 & 731 & 3.1 & $7.74(3.21,18.62)$ & 2004 & & & \\
\hline Akhter & 45 & 119 & 68 & 361 & 5.6 & $2.62(1.66,4.13)$ & 2004 & & . & \\
\hline De Silva & 44 & 161 & 219 & 1,055 & 6.2 & $1.44(0.98,2.09)$ & 2005 & & 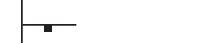 & \\
\hline Jose & 58 & 223 & 316 & 1,631 & 6.6 & $1.46(1.06,2.02)$ & 2006 & & 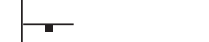 & \\
\hline Khan & 628 & 2,060 & 879 & 4,475 & 7.8 & $1.79(1.59,2.02)$ & 2006 & & T & \\
\hline Cowie & 26 & 98 & 35 & 201 & 4.8 & $1.71(0.96,3.05)$ & 2006 & & & \\
\hline Owan & 1,095 & 1,419 & 3,215 & 4,633 & 7.7 & $1.49(1.30,1.71)$ & 2006 & & - & \\
\hline Cioffi & 11 & 16 & 12 & 63 & 2.0 & $9.35(2.73,31.99)$ & 2007 & & & $\rightarrow$ \\
\hline Chittineni & 10 & 107 & 17 & 402 & 3.4 & $2.33(1.04,5.26)$ & 2007 & & . & \\
\hline Iglesias & 47 & 221 & 49 & 461 & 5.8 & $2.27(1.47,3.52)$ & 2008 & & 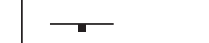 & \\
\hline Hata & 29 & 275 & 1 & 101 & 0.9 & $11.79(1.58,87.72)$ & 2010 & & & $\rightarrow$ \\
\hline Kociol & 1,261 & 3,581 & 5,601 & 16,482 & 7.9 & $1.06(0.98,1.14)$ & 2010 & & & \\
\hline Lassus & 18 & 46 & 67 & 246 & 4.3 & $1.72(0.89,3.31)$ & 2010 & & 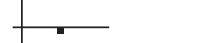 & \\
\hline Herout & 25 & 252 & 16 & 515 & 4.3 & $3.43(1.80,6.56)$ & 2010 & & . & \\
\hline Damman & 30 & 106 & 76 & 894 & 5.4 & $4.25(2.62,6.89)$ & 2010 & & 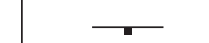 & \\
\hline Belziti & 12 & 46 & 25 & 154 & 3.5 & $1.82(0.83,3.99)$ & 2010 & & . & \\
\hline Breidthardt & 49 & 136 & 171 & 521 & 6.1 & $1.15(0.78,1.71)$ & 2011 & & - & \\
\hline Voors & 11 & 68 & 7 & 157 & 2.6 & $4.14(1.53,11.19)$ & 2011 & & 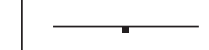 & \\
\hline Total $(95 \%$ CI) & & 9,861 & & 34,522 & 100 & $1.99(1.63,2.42)$ & & & $\Delta$ & \\
\hline Total events & 3,572 & & 11,043 & & & & & & & \\
\hline Heterogeneity: & $\tau^{2}=0.1$ & $3, x^{2}=1$ & 6.49 , d.f. & $=19(p<$ & $.00001), I^{2}=$ & $=87 \%$ & 0.05 & 0.2 & 5 & 20 \\
\hline Test for overall & I effect: Z & $=6.81$ & $<0.000$ & & & & & No WRF & WRF & \\
\hline
\end{tabular}

Fig. 10. Meta-analysis of WRF, indicating an association with poor clinical outcome [unpubl. data].

to controls. Further work by Damman et al. [42] in tubular damage in chronic heart failure, as indicated by elevated urinary NGAL, N-acetyl- $\beta$-D-glucosamidase (NAG) and kidney injury molecule-1 (KIM-1), showed that tubular damage was increased in patients with chronic heart failure compared to controls; however, measures adjusted for eGFR showed that, unlike NAG and KIM-1, urinary NGAL did not increase significantly between those chronic heart failure patients with CKD and those without $\mathrm{CKD}$, suggesting that it is not a suitable marker in the chronic setting.

Interestingly, data by Alvelos et al. [43] investigating outcomes in acute heart failure show that higher plasma NGAL levels predict 3-year mortality independently of eGFR. Similar work by Damman et al. [44] (as part of the GISSI-HF Study [45]) investigated outcomes in chronic heart failure in relation to markers of tubular damage, including urinary NGAL, identifying a correlation between increased urinary NGAL expression and the combined endpoint of cardiovascular hospitalisation and mortality, independent of GFR.

NGAL: Ready for Routine Clinical Use?
While worsening renal function (WRF) might be associated with poor outcome, transient WRF may be tolerable and may be dependent on a hereto unknown underlying cause, as evidenced by the difficulty in predicting the deterioration in renal function. There are difficulties in assessing WRF with NGAL levels, and studies demonstrate a modest association between urinary NGAL and WRF [46-48]. However, recent analysis of data from the GISSI-HF study in the deterioration of eGFR in chronic heart failure indicated that NGAL seems to predict WRF over a long period of time (fig. 10,11) [Damman et al., unpubl. data].

Urinary and plasma NGAL levels are elevated in both acute and chronic heart failure, and plasma levels reflect the severity of the underlying disease. Urinary NGAL predicts outcome and deterioration of GFR in chronic heart failure. Results regarding plasma NGAL and change in GFR in acute heart failure are mixed. However, the ongoing AKINESIS study [49] will provide more definitive data on the time course of urinary and plasma NGAL with respect to WRF in acute heart failure. 


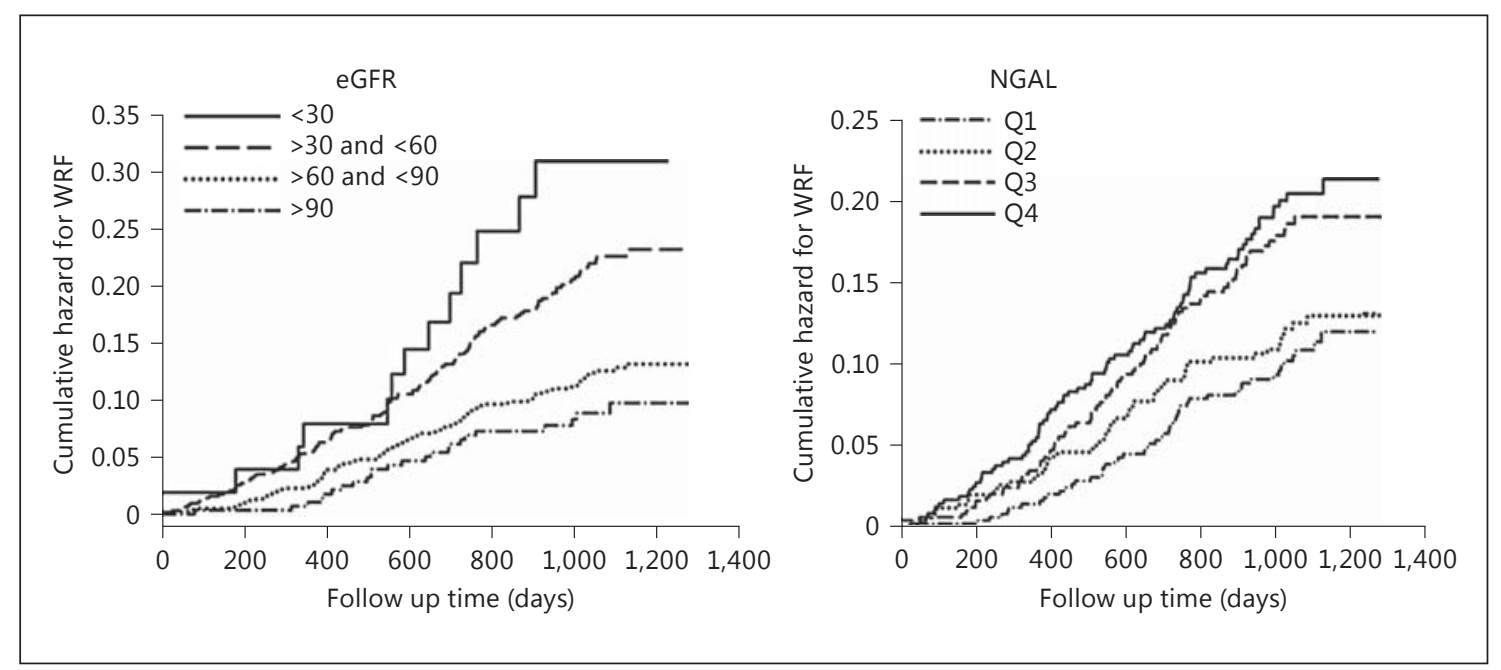

Fig. 11. Long-term follow-up of eGFR and NGAL levels, indicating that NGAL is predictive of WRF [unpubl. data].

\section{NGAL and Renal Replacement Therapy in Intensive Care [50]}

The diagnostic applications of NGAL lie within risk identification and stratification, bundling of renal therapies, triage decision-making, the ongoing assessment of interventions, and in acting as enrolment criteria for future clinical trials. Yet amid much evidence for the readiness of NGAL for clinical application in the ICU and emergency department, the means of translating knowledge of NGAL behaviour into clinical protocol is still undefined.

In studying the use of plasma and urinary NGAL in critically ill patients, Bagshaw et al. [51] demonstrated that patients who developed worsening AKI had a higher serum level of plasma NGAL compared to those whose AKI did not deteriorate. In this study, renal replacement therapy (RRT) was associated with higher serum levels of plasma NGAL compared with patients who did not progress to RRT. In a separate study of a cardiac surgery patient cohort that developed AKI, plasma NGAL best discriminated the patients who developed worsening AKI [52]. These patients demonstrated larger relative changes in $\mathrm{sCr}$ on the day of diagnosis of AKI, as well as having higher incidences of RRT and in-hospital death, suggesting that worsening AKI may be an important outcome measure in terms of decision support for other interventions.

A systematic review by Haase et al. [53] demonstrated the predictive value of NGAL for RRT. For plasma NGAL levels $>150 \mathrm{ng} / \mathrm{ml}$, the diagnostic odds ratio for subsequent need of RRT equalled 12.4. Further studies measuring urinary NGAL for the discrimination of AKI from other syndromes, analysing a composite outcome (comprising renal consultation, dialysis initiation, admission to the ICU, or in-hospital mortality), found that patients with NGAL levels $>130 \mathrm{ng} / \mathrm{ml}$ had an odds ratio of 25 for the composite outcome [54].

Treatment strategies that combine both diagnostics with therapeutics - 'theragnostics' - for individual patients allow for the identification of patients most likely to be either helped or harmed by a new therapy. By quantifying risk, an effective therapy can be modified for the most likely benefit, or a therapy that may be harmful or that is associated with adverse events can be avoided. An instructive example of theragnostics is the human epidermal growth factor receptor 2 (HER2) test. HER2 overexpression is a risk factor for aggressive breast cancers; its corresponding therapy is trastuzumab, a monoclonal antibody that binds to the HER2 receptor. By analogy, plasma NGAL concentrations can be paired with an intervention such as RRT, where patients who would receive the greatest benefit would be selected for that therapy. Such a method would achieve improvements in clinical decision support (fig. 12).

Better therapeutic selection for individual patients demands the use of clinical risk identification tools and biomarkers in conjunction. The process by which current knowledge of NGAL could be translated into useful clinical protocol must acknowledge that, while there are 
Fig. 12. Plasma NGAL concentrations could be integrated into clinical decision-making by helping to stratify risk groups in patients, thereby aiding patient selection for treatments such as RRT $[55,56]$.
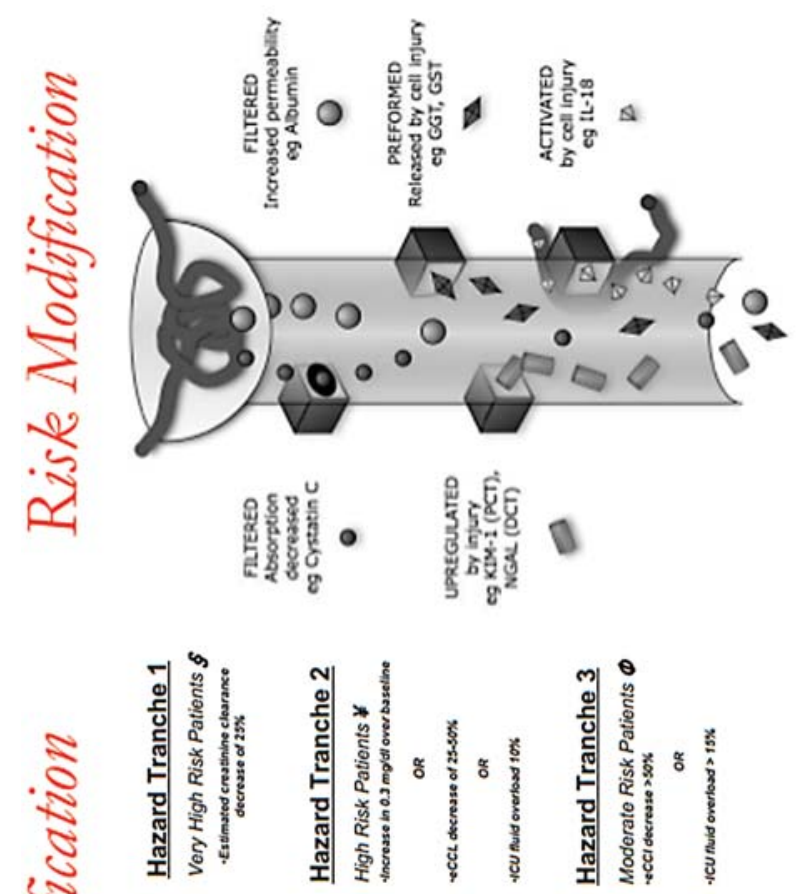

密 趈

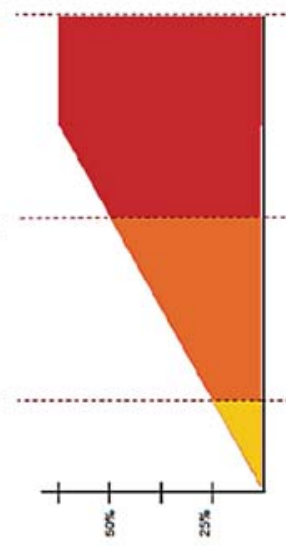

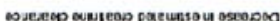
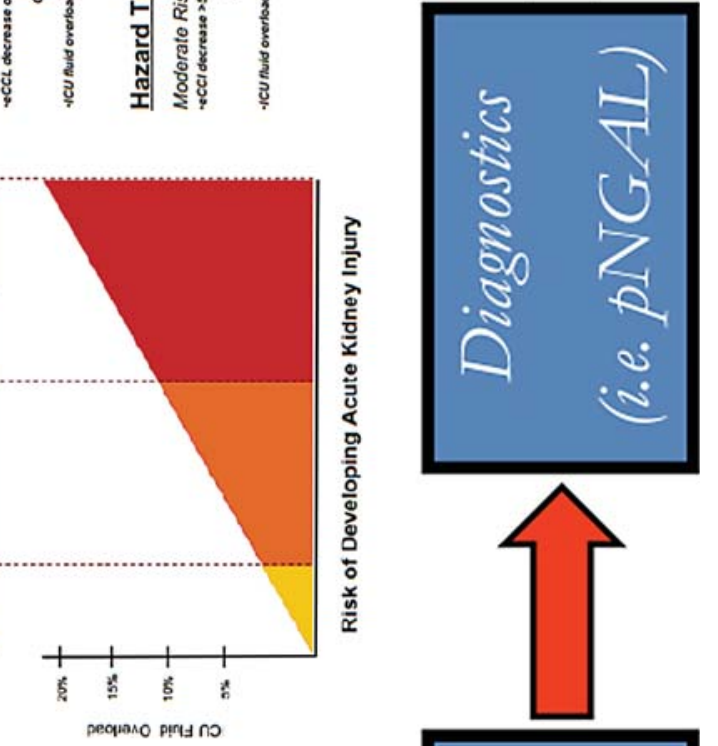



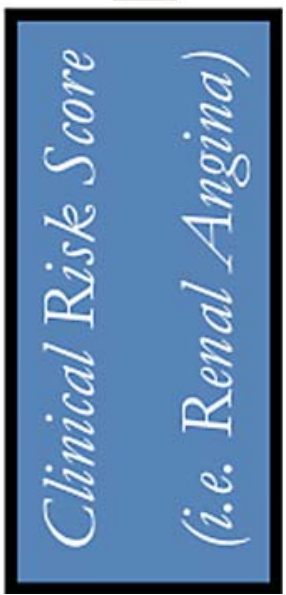


Fig. 13. Outline of the multicentre prospective emergency department study investigating the sensitivity of NGAL as an additional biomarker to $\mathrm{Cr}$ in early risk evaluation of AKI [58].

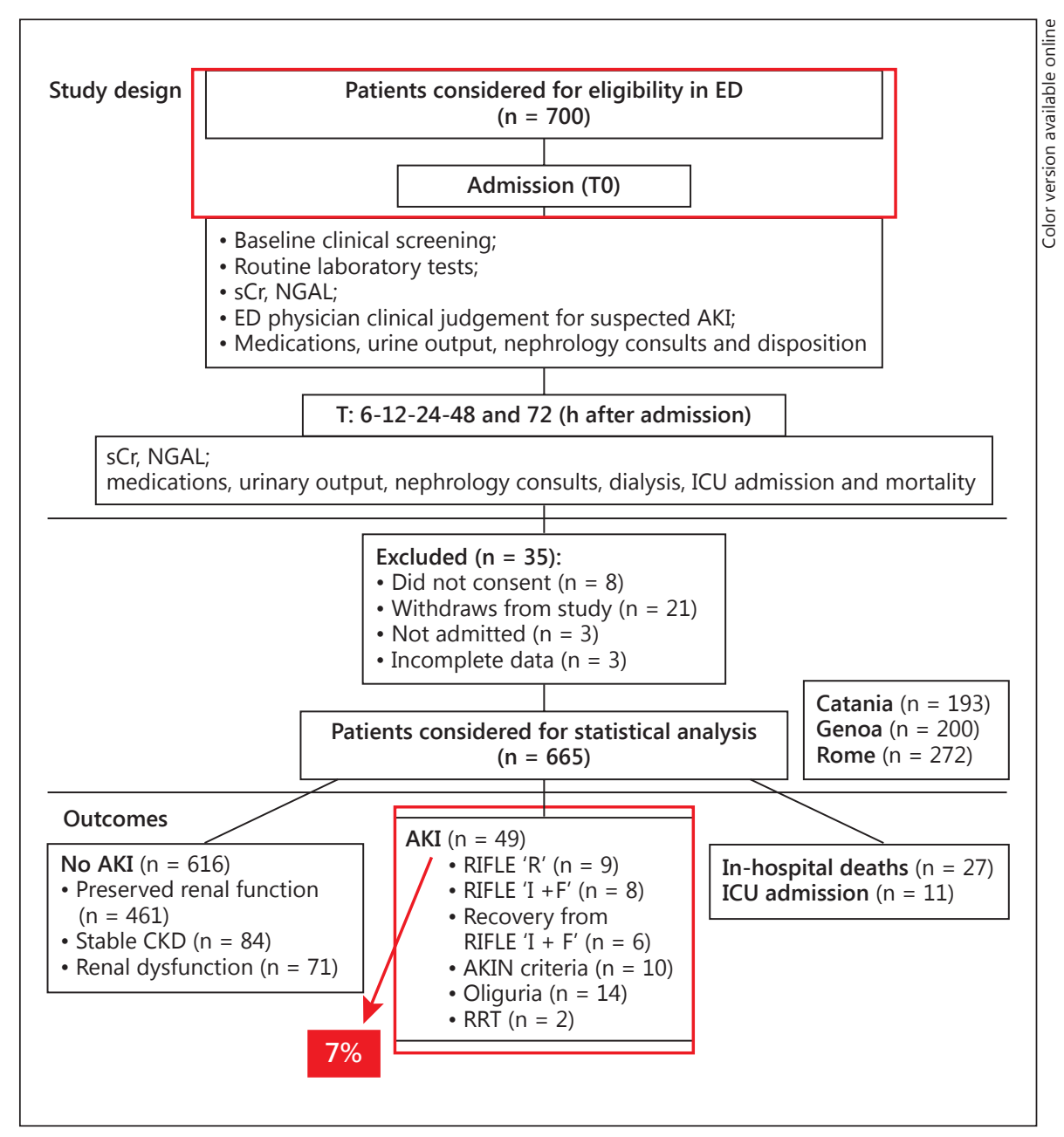

many established risk factors for AKI, AKI arises from a multitude of syndromes. In addition, its place as a biomarker conferring unique information amid a battery of other markers must be considered.

\section{NGAL in the Emergency Department [57]}

AKI incidence, which is around 7\% according to a recent multicentre prospective emergency department study [58], is likely to increase worldwide due to the ageing population [57]. Persistent factors, including high AKI-related mortality (especially in the setting of multiple organ failure [57]), overcrowding of emergency departments [59], and the limited utility of the RIFLE criteria in an emergency setting due to a significant paucity of patients' baseline $\mathrm{Cr}$ measures, suggest that improved biomarkers are a continuing and pressing need in emergency medicine.
Di Somma et al. [58] recently demonstrated the sensitivity of NGAL in early risk evaluation of AKI development in the emergency department (fig. 13), evidencing the use of NGAL in conjunction with $\mathrm{Cr}$ to strengthen clinical judgement. They also found the predictive ability of POC testing of BNP and NGAL for the assessment of WRF in patients admitted to the emergency department. Their analysis of emergency department admissions described a $16.2 \%$ incidence of acute decompensate heart failure, of whom $20.4 \%$ develop AKI.

In subsequent work by Januzzi et al. the incidence of WRF in heart failure patients was found to be $25 \%$ with a mortality rate of $40 \%$ at 30 days, and a hospital stay of 12 days (compared to 5 days in patients without WRF). In addition, measures of BNP $>500 \mathrm{pg} / \mathrm{ml}$ and NGAL $\sim 200$ $\mathrm{pg} / \mathrm{ml}$ predicted the occurrence of WRF, and in-hospital death, over subsequent days in these patients [Di Somma et al., unpubl. data]. 
There is considerable evidence indicating that NGAL is a sensitive early marker of injury that is highly suited to AKI risk evaluation. These data strongly suggest that future investigations should integrate NGAL with existing clinical markers in order to refine the assessment of risk and target individual patient therapies in the emergency room.

\section{Conclusions}

Our understanding of the pathophysiology of AKI remains relatively poor. Further study into the role of NGAL in both kidney injury and cardiovascular disease could well improve knowledge and, fundamentally, improve patient stratification in clinical trials. Critically, clinical judgement, prognosis and management of the various pathologies that lead to AKI would greatly benefit from its adoption. Its place as a marker of kidney injury, together with $\mathrm{Cr}$, a marker of function, can provide a more comprehensive snapshot in the highly dynamic course that AKI may take.

Strong evidence has been provided for the use of NGAL in a variety of settings: in predicting fluid accumulation and kidney injury in paediatric AKI; in cases of suspected sepsis; in fluid resuscitation of severely burned patients; as a biomarker of DGF in kidney transplantation; in heart disease and heart failure, and in RRT in the ICU and in emergency department decision-making. While some studies are ongoing, other areas, such as sepsis, heart failure and severe burns, would benefit from wider, more comprehensive studies.

NGAL's route into clinical management protocols is in the definition of how it can be applied to risk calculation and stratification within a specific AKI scenario. Quicker testing by way of POC devices will be instrumental in improving ongoing patient management as well as triage decision-making.

\section{References}

1 Legrand M: NGAL: A biomarker of injury, not function. Presentation in A. Lewington (Chair), NGAL: Ready for Routine Clinical Use? An International Perspective. Symposium at 31st International Vicenza Course on Critical Care Nephrology, Vicenza, 2013.

$\checkmark 2$ Lameire NH, Vanholder RC, Van Biesen WA: How to use biomarkers efficiently in acute kidney injury. Kidney Int 2011;79:1047-1050.

-3 Vanmassenhove J, Vanholder R, Nagler E, Van Biesen W: Urinary and serum biomarkers for the diagnosis of acute kidney injury: an in-depth review of the literature. Nephrol Dial Transplant 2013;28:254-273.

4 Legrand M, Collet C, Gayat E, Henao J, Giraudeaux V, Mateo J, Launay JM, Payen D: Accuracy of urine NGAL commercial assays in critically ill patients. Intensive Care Med 2013;39:541-542.

5 Paragas N, Qiu A, Zhang Q, Samstein B, Deng SX, Schmidt-Ott KM, Viltard M, Yu W, Forster CS, Gong G, Liu Y, Kulkarni R, Mori K, Kalandadze A, Ratner AJ, Devarajan P, Landry DW, D'Agati V, Lin CS, Barasch J: The NGAL reporter mouse detects the response of the kidney to injury in real time. Nat Med 2011;17:216-222.

6 Goldstein SL: Using NGAL to direct care in pediatric research. Presentation in A. Lewington (Chair), NGAL: Ready for Routine Clinical Use? An International Perspective. Symposium at 31st International Vicenza Course on Critical Care Nephrology, Vicenza, 2013.
7 Goldstein SL: Use of biomarkers to optimize fluid dosing, CRRT initiation and discontinuation in pediatric ICU patients with AKI. Current Controlled Trials. 2012. http://clinicaltrials.gov/ct2/show/NCT01416298.

8 Sutherland SM, Zappitelli M, Alexander SR, Chua AN, Brophy PD, Bunchman TE, Hackbarth R, Somers MJ, Baum M, Symons JM, Flores FX, Benfield M, Askenazi D, Chand D, Fortenberry JD, Mahan JD, McBryde K, Blowey D, Goldstein SL: Fluid overload and mortality in children receiving continuous renal replacement therapy: The Prospective $\mathrm{Pe}$ diatric Continuous Renal Replacement Therapy Registry. Am J Kidney Dis 2010;55:316325.

-9 Ricci Z, Luciano R, Favia I, Garisto C, Muraca M, Morelli S, Di Chiara L, Cogo P, Picardo S: High-dose fenoldopam reduces postoperative neutrophil gelatinase-associated lipocaline and cystatin $C$ levels in pediatric cardiac surgery. Crit Care 2011;15:R160.

10 Hur M: Plasma neurophil gelatinase-associated lipocalin as a biomarker for acute kidney injury in critically ill patients with suspected sepsis. Presentation in A. Lewington (Chair), NGAL: Ready for Routine Clinical Use? An International Perspective. Symposium at 31st International Vicenza Course on Critical Care Nephrology, Vicenza, 2013.

11 Kim H, Hur M, Cruz DN, Moon HW, Yun YM: Plasma neutrophil gelatinase-associated lipocalin as a biomarker for acute kidney injury in critically ill patients with suspected sepsis. Clin Biochem 2013;46:1414-1418.
12 Levy MM, Fink MP, Marshall JC, Abraham E, Angus D, Cook D, Cohen J, Opal SM, Vincent JL, Ramsay G: 2001 SCCM/ESICM/ACCP/ ATS/SIS International Sepsis Definitions Conference. Crit Care Med 2003;31:12501256.

13 Koyner JL, Vaidya VS, Bennett MR, Ma Q, Worcester E, Akhter SA, Raman J, Jeevanandam V, O’Connor MF, Devarajan P, Bonventre JV, Murray PT: Urinary biomarkers in the clinical prognosis and early detection of acute kidney injury. Clin J Am Soc Nephrol 2010;5: 2154-2165.

14 Assicot M, Bohuon C, Gendrel D, Raymond J, Carsin H, Guilbaud J: High serum procalcitonin concentrations in patients with sepsis and infection. Lancet 1993;341:515-518.

15 Tang BM, Eslick GD, Craig JC, McLean AS: Accuracy of procalcitonin for sepsis diagnosis in critically ill patients: systematic review and meta-analysis. Lancet Infect Dis 2007;7:210 217.

16 Hur M, Moon HW, Yun YM, Kim KH, Kim HS, Lee KM: Comparison of diagnostic utility between procalcitonin and C-reactive protein for the patients with blood culture-positive sepsis (in Korean). Korean J Lab Med 2009;29: 529-535.

17 Tran N, Howell EC: BNP and NGAL for acute resuscitation in severely burned patients. Presentation in A. Lewington (Chair), NGAL: Ready for Routine Clinical Use? An International Perspective. Symposium at 31st International Vicenza Course on Critical Care Nephrology, Vicenza, 2013. 
-18 Mosier MJ, Pham TN, Klein MB, Gibran NS, Arnoldo BD, Gamelli RL, Tompkins RG, Herndon DN: Early acute kidney injury predicts progressive renal dysfunction and higher mortality in severely burned adults. J Burn Care Res 2010;31:83-92.

19 Baxter C, Shires T: Physiologic response to crystalloid resuscitation in severe burns. Ann NY Acad Sci 1968;150:874-893.

20 Friese RS, Dineen S, Jennings A, Pruitt J, McBride D, Shafi S, Frankel H, Gentilello LM: Serum B-type natriuretic peptide: a marker of fluid resuscitation after injury? J Trauma 2007;62:1346-1350.

21 Devarajan P: Review: Neutrophil gelatinaseassociated lipocalin: a troponin-like biomarker for human acute kidney injury. Nephrology 2010;15:419-428.

22 Ronco C, Haapio M, House AA, Anavekar N, Bellomo R: Cardiorenal syndrome. J Am Coll Cardiol 2008;52:1527-1539.

23 Cantaluppi V: Plasma NGAL is an early biomarker of delayed graft function and CNI nephrotoxicity in kidney transplantation from extended criteria donors. Presentation in A. Lewington (Chair), NGAL: Ready for Routine Clinical Use? An International Perspective. Symposium at 31st International Vicenza Course on Critical Care Nephrology, Vicenza, 2013.

-24 Wolfe RA, Vashby VB, Milford EL, Ojo AO, Ettenger RE, Agodoa LY, Held PJ, Port FK: Comparison of mortality in all patients on dialysis, patients on dialysis awaiting transplantation, and recipients of a first cadaveric transplant. N Engl J Med 1999;341:17251730.

25 Arns W, Citterio F, Campistol JM: 'Old-forold' - new strategies for renal transplantation. Nephrol Dial Transplant 2007;22:336-341.

-26 Quiroga I, McShane P, Koo DDH, Gray D, Friend PJ, Fuggle S, Darby C: Major effects of delayed graft function and cold ischaemia time on renal allograft survival. Nephrol Dial Transplant 2006;21:1689-1696.

-27 Halloran PF: T cell-mediated rejection of kidney transplants: a personal viewpoint. Am J Transplant 2010;10:1126-1134.

28 Siedlecki A, Irish W, Brennan DC: Delayed graft function in the kidney transplant. Am J Transplant 2011;11:2279-2296.

29 Hall IE, Yarlagadda SG, Coca SG, et al: Wang Z, Doshi M, Devarajan P, Han WK, Marcus RJ, Parikh CR: IL-18 and urinary NGAL predict dialysis and graft recovery after kidney transplantation. J Am Soc Nephrol 2010;21: 189-197.

- 30 Viau A, El Karoui K, Laouari D, Burtin M, Nguyen C, Mori K, Pillebout E, Berger T, Mak TW, Knebelmann B, Friedlander G, Barasch J, Terzi F: Lipocalin-2 is essential for chronic kidney disease progression in mice and humans. J Clin Invest 2010;120:4065-4076.
31 Cruz DN: Beyond the kidneys: NGAL as a biomarker of cardiovascular disease. Presentation in A. Lewington (Chair), NGAL: Ready for Routine Clinical Use? An International Perspective. Symposium at 31st International Vicenza Course on Critical Care Nephrology, Vicenza, 2013.

32 Hemdahl A-L, Gabrielsen A, Zhu C, Eriksson P, Hedin U, Kastrup J, Thorén P, Hansson GK: Expression of neutrophil gelatinase-associated lipocalin in atherosclerosis and myocardial infarction. Arterioscler Thromb Vasc Biol 2006;26:136-142.

-33 Folkesson M, Kazi M, Zhu C, Silveira A, Hemdahl AL, Hamsten A, Hedin U, Swedenborg J, Eriksson P: Presence of NGAL/MMP-9 complexes in human abdominal aortic aneurysms. Thromb Haemost 2007;98:427-433.

34 Cruz DN, Gaiao S, Maisel A, Ronco C, Devarajan P: Neutrophil gelatinase-associated lipocalin as a biomarker of cardiovascular disease: a systematic review. Clin Chem Lab Med 2012;50:1533-1545.

35 Maisel AS, Mueller C, Fitzgerald R, Brikhan R, Hiestand BC, Iqbal N, Clopton P, van Veldhuisen DJ: Prognostic utility of plasma neutrophil gelatinase-associated lipocalin in patients with acute heart failure: The NGAL EvaLuation Along with B-type NaTriuretic Peptide in acutely decompensated heart fail ure (GALLANT) trial. Eur J Heart Fail 2011; 13:846-851.

-36 Nymo S H, Ueland T, Askevold ET, Flo TH, Kjekshus J, Hulthe J, Wikstrand J, McMurray J, Van Veldhuisen DJ, Gullestad L, Aukrust P, Yndestad A: The association between neutrophil gelatinase-associated lipocalin and clinical outcome in chronic heart failure: results from CORONA. J Intern Med 2011;271:436443.

37 Daniels LB, Barrett-Connor E, Clopton P, Laughlin GA, Ix JH, Maisel AS: Plasma neutrophil gelatinase-associated lipocalin is independently associated with cardiovascular disease and mortality in community-dwelling older adults: The Rancho Bernardo Study. J Am Coll Cardiol 2012:59:1101-1109.

38 Damman K: NGAL in heart failure. Presentation in Al Lewington (Chair), NGAL: Ready for Routine Clinical Use? An International Perspective. Symposium at 31st International Vicenza Course on Critical Care Nephrology, Vicenza, 2013.

39 Hillege HL, Girbes ARJ, de Kam PJ, Boomsma F, de Zeeuw D, Charlesworth A, Hampton JR, van Veldhuisen DJ: Renal function, neurohormonal activation, and survival in patients with chronic heart failure. Circulation 2000; 102:203-210.

40 Entin-Meer M, Ben-Shoshan J, Maysel-Auslender S, Levy R, Goryainov P, Schwartz I, Barshack I, Avivi C, Sharir R, Keren G: Accelerated renal fibrosis in cardiorenal syndrome is associated with long-term increase in urine neutrophil gelatinase-associated lipocalin levels. Am J Nephrol 2012;36:190-200.
41 Damman K, van Veldhuisen DJ, Navis G, Voors AA, Hillege HL: Urinary neutrophil gelatinase associated lipocalin (NGAL), a marker of tubular damage, is increased in patients with chronic heart failure. Eur J Heart Fail 2008; 10:997-1000.

-42 Damman K, Van Veldhuisen DJ, Navis G, Vaidya VS, Smilde TD, Westenbrink BD, Bonventre JV, Voors AA, Hillege HL: Tubular damage in chronic systolic heart failure is associated with reduced survival independent of glomerular filtration rate. Heart 2010;96: 1297-1302.

43 Alvelos M, Lourenço P, Dias C, Amorim M, Rema J, Leite AB, Guimarães JT, Almeida P, Bettencourt P: Prognostic value of neutrophil gelatinase-associated lipocalin in acute heart failure. Int J Cardiol 2013;165:51-55.

44 Damman K, Masson S, Hillege HL, Maggioni AP, Voors AA, Opasich C, van Veldhuisen DJ, Montagna L, Cosmi F, Tognoni G, Tavazzi L, Latini R: Clinical outcome of renal tubular damage in chronic heart failure. Eur Heart J 2011;32:2705-2712.

45 Tavazzi L, Tognoni G: GISSI-HF: effects of n-3 PUFA and rosuvastatin on mortalitymorbidity of patients with symptomatic CHF. Current Controlled Trials. 2006. http://clinicaltrials.gov/ct2/show/NCT00336336.

46 Collins SP, Hart KW, Lindsell CJ, Fermann GJ, Weintraub NL, Miller KF, Roll SN, Sperling MI, Sawyer DB, Storrow AB: Elevated urinary neutrophil gelatinase-associated lipocalcin after acute heart failure treatment is associated with worsening renal function and adverse events. Eur J Heart Fail 2012;14: 1020-1029.

47 Aghel A, Shrestha K, Mullens W, Borowski A, Tang WH: Serum neutrophil gelatinase-associated lipocalin (NGAL) in predicting worsening renal function in acute decompensated heart failure. J Card Fail 2010;16:49-54.

48 Breidthardt T, Socrates T, Drexler B, Noveanu M, Heinisch C, Arenja N, Klima T, Züsli C, Reichlin T, Potocki M, Twerenbold R, Steiger J, Mueller C: Plasma neutrophil gelatinase-associated lipocalin for the prediction of acute kidney injury in acute heart failure. Crit Care 2012;16:R2.

49 Maisel A, Murray P: Acute kidney injury neutrophil gelatinase-associated lipocalin $(\mathrm{N}$ GAL) evaluation of symptomatic heart failure study (AKINESIS). Current Controlled Trials. 2011. http://clinicaltrials.gov/ct2/show/ NCT01291836.

50 Bagshaw SM: NGAL and renal replacement therapy in the ICU. Presentation in A. Lewington (Chair), NGAL: Ready for Routine Clinical Use? An International Perspective. Symposium at 31st International Vicenza Course on Critical Care Nephrology, Vicenza, 2013. 
51 Bagshaw SM, Bennett M, Haase M, HaaseFielitz A, Egi M, Morimatsu H, d'Amico G, Goldsmith D, Devarajan P, Bellomo R: Plasma and urine neutrophil gelatinase-associated lipocalin in septic versus non-septic acute kidney injury in critical illness. Intensive Care Med 2010;36:452-461.

52 Koyner JL, Garg AX, Coca SG, Sint K, Thiessen-Philbrook H, Patel UD, Shlipak MG, Parikh CR; TRIBE-AKI Consortium: Biomarkers predict progression of acute kidney injury after cardiac surgery. J Am Soc Nephrol 2012;23:905-914.

53 Haase M, Bellomo R, Devarajan P, Schlattmann P, Haase-Fielitz A; NGAL Meta-Analysis Investigator Group: Accuracy of neutrophil gelatinase-associated lipocalin (NGAL) in diagnosis and prognosis in acute kidney injury: a systematic review and meta-analysis. Am J Kidney Dis 2009;54:1012-1024.
54 Nickolas TL, O’Rourke MJ, Yang J, Sise ME, Canetta PA, Barasch N, Buchen C, Khan F, Mori K, Giglio J, Devarajan P, Barasch J: Sensitivity and specificity of a single emergency department measurement of urinary neutrophil gelatinase-associated lipocalin for diagnosing acute kidney injury. Ann Intern Med 2008; 148:810-819.

55 Basu RK, Chawla LS, Wheeler DS, Goldstein SL: Renal angina: an emerging paradigm to identify children at risk for acute kidney injury. Pediatr Nephrol 2012;27:1067-1078.

56 Goldstein SL, Chawla LS: Renal angina. Clin J Am Soc Nephrol 2010;5:943-949.
57 Di Somma S: NGAL use and experiences for AKI detection in the emergency department. Presentation in A. Lewington (Chair), NGAL: Ready for Routine Clinical Use? An International Perspective. Symposium at 31st International Vicenza Course on Critical Care Nephrology, Vicenza, 2013.

58 Di Somma S, Magrini L, De Berardinis B, Marino R, Ferri E, Moscatelli $\mathrm{P}$, Ballarino $\mathrm{P}$, Carpinteri G, Noto P, Gliozzo B, Paladino L, Di Stasio E: Additive value of blood neutrophil gelatinase-associated lipocalin to clinical judgement in acute kidney injury diagnosis and mortality prediction in patients hospitalized from the emergency department. Crit Care 2013;17:R29.

59 Kellermann AL: Crisis in the emergency department. N Engl J Med 2006;355:1300-1303. 